\title{
Hybrid optical communications for supporting the Palapa Ring network
}

Ucuk Darusalam $^{1}$, Fitri Yuli Zulkifli ${ }^{2}$, Purnomo Sidi Priambodo ${ }^{3}$, Eko Tjipto Rahardjo ${ }^{4}$

${ }^{1}$ Department of Informatics, Faculty of Information \& Communications Technology, Universitas Nasional, Indonesia

${ }^{2,3,4}$ Department of Electrical Engineering, Faculty of Engineering, Universitas Indonesia

\begin{abstract}
Article Info
Article history:

Received Sep 1, 2019

Revised Oct 15, 2019

Accepted Jan 31, 2020

\section{Keywords:}

Free-space optical communications

Hybrid optical communications

Optical band pass filter

Optical relaying networks

Palapa Ring

ABSTRACT

In order to connecting villages in rural area with a city, a hybrid optical communication is proposed. The Optical fiber communications that are implemented as a backbone on the Palapa Ring network has an opportunity to be expanded to reach rural area through the implementation of free-space optical communications (FSO) as the optical relaying networks (ORN). The major problem of FSO as the ORN is turbulence effects induce an optical propagation. In this research, FSO as the ORN implements novel technique to improve the performance of hybrid FSO where the amplification of signal is produced through serial configuration of optical amplifiers in cascaded meanwhile to reduce the noise in the end of receiver, optical band pass filter is implemented. The simulation of hybrid FSO is performed in Optisystem 7.0 where ORN is implemented in two nodes. The length of optical fiber connection to FSO is set to be constant at $75 \mathrm{~km}$. The range of optical propagation in FSO is set at $1-9.4 \mathrm{~km}$. The results of simulation show that at the range of $1-8 \mathrm{~km}$ of optical propagation under atmospheric turbulence, range values for SNR and BER are achieved at 46.23-26.61 dB and $6.7 \times 10^{-17}-1.5 \times 10^{-6}$, respectively.
\end{abstract}

This is an open access article under the $\underline{C C B Y-S A}$ license.

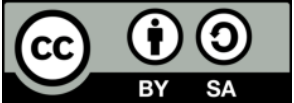

\section{Corresponding Author:}

Ucuk Darusalam,

Department of Informatics,

Faculty of Information \& Communications Technology,

Universitas Nasional, Indonesia,

Jl. Sawo Manila No. 61, Pejaten, Pasar Minggu, Jakarta 12520.

Email: ucuk.darusalam@gmail.com

\section{INTRODUCTION}

Indonesia is the largest archipelago nation in the world where consist about 17,504 islands that is stretched out between Indian to Pacific oceans in the length of 3,977 miles. Those islands are also the ring of fire from Asia to Pacific as well. The demography for about 270 million people are not well distributed along these is lands as well. Mostly, the occupant distribution of people are concentrated in major islands which are Java, Sumatra, Kalimantan, Bali, Sulawesi, and West Papua. Meanwhile others of occupant are distributed in small islands. Those occupant of people are also distributed in 74,093 villages where about $73.89 \%$ is in poor economic condition, $22.94 \%$ is in very poor economic condition, and $1.53 \%$ is distributed in the oceanic border of Republic Indonesia territorial. The aforementioned of geographical and demography conditions cause the connectivity of information is the major problem for all provinces.

In order to solve the problem of connectivity, since 2007 the government of Republic Indonesia has initiated the gigantic of telecommunication network that is intended to connect all provinces, cities and districts in a unity platform of infrastructure that is so called as the Palapa Ring [1-7]. The infrastructure 
of telecommunication that has been developed by the government is the passive optical network (PON) that is stretched out about $8479 \mathrm{~km}$ connecting 34 provinces, 400 cities, and 457 districts. The Palapa Ring is consist of three regions which are west-, center- and east-region where each of one is planned to have bandwidth at the rate of $100 \mathrm{Gbps}$ (upgradeable to $160 \mathrm{Gbps}$ ) through wavelength division multiplexing (WDM) technology. Until now, 2019, the status of the Palapa Ring is under developed for east region where the progress has achieved $88.14 \%$ meanwhile for west-and center-region has already operated. The Palapa Ring is set to be the unity of communication platform that unites all of geographical condition such as oceans, is lands, and mountains. Those by this unity of communication platform, the transfer of information can be enhanced throughout the villages even in border area of Indonesia territory. Hence, the expectation or long term goal that has been set by the government of Republic Indonesia that the potential economic in all villages can be strengthen in more advance especially the villages that has economic status of poor and very poor as well as in the outside of island near the border of the nation.

In order to support the goal of connectivity by the government of Republic Indonesia, a communication platform should be integrated with PON where connectivity between district and city can be expanded to reach villages or rural area. If district or city has an infrastructure of telecommunication with high data rate, the question is how to deliver or distribute the huge of information to village? Meanwhile the average distance between district and city with village is in the order of tenth kilometers. To answer this question, important thing should be considered that the goal of connectivity not just merely connecting the unreachable area but also to enhance the communication of broadband system supporting the internet connection between district and city with village in the remote area. For this reason, high speed and high data rate transmission should be emphasized as major requirement to integrate PON with a scheme of proposed communication platform. Hence, a scheme of optical communication which is a free-space optical (FSO) communication or wireless optical communication is one of the best candidate to be proposed as the physical platform to be integrated with PON that has already been setup in WDM. FSO is a communications platform that has benefits on free-licensed, high data rate, low cost economy development, and can be integrated with any others scheme of telecommunications such satellite-, microwave radio-, and terrestrial-platform [8]. Thus, FSO has an opportunity to be integrated with PON WDM of the Palapa Ring as the optical relaying to connecting between district or city with village in the remote area as well, as shown in Figure 1.

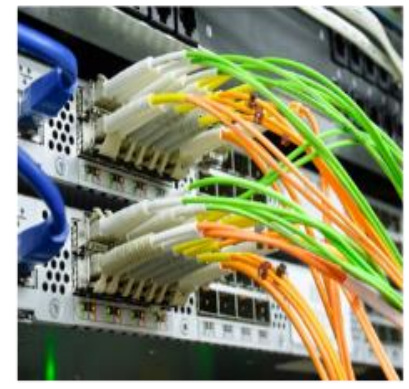

Backbone of optical fiber communications in the districts/cities from The Palapa Ring.
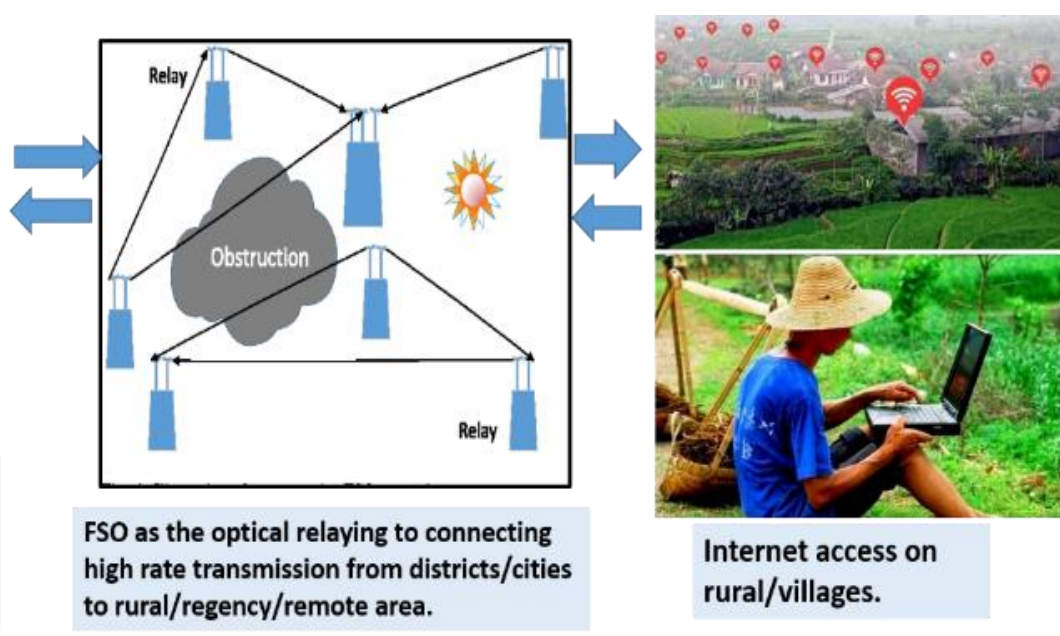

Figure 1. FSO as the ORN to connecting backbone of internet from Palapa Ring to rural area thus villages can have access to information

The integration of PON with FSO is so called as hybrid optical communications where all optical signal is delivered in the network of Palapa Ring. The performances of PON as the optical fiber communications platform is very high quality where the signal in the speed of light and high bandwidth are well distributed in the network. Hence, FSO should be designed in the characteristics where the quality of performance and bandwidth capacity are also well support. In the hybrid configuration of optical communications, FSO is designed as the ORN forwarding high data rates at the scale of 100 Gbps and connecting the path link in the order of tenth kilometers between district and city to village. FSO has many benefits than other platform of terrestrial communication such as wireless radio. 
If the integration PON of the Palapa Ring Network uses radio wireless, some points should be considered where the capacity of data rate transmission is limited, fading effect of radio transmission, and limit distance of network are also major limitation. Thus, FSO in the integration scheme with PON WDM has the main function as the last mile access for users in the village or remote area from the district or city.

Hybrid optical communications has been developed world wide as the solution to penetrate the barrier between sources to last access user in order to expand the network as closer as possible [9-14]. The emerging communications between optical platform and radio based frequency or RF has been implemented in the scheme or radio over free-space optical technology (RoFSO) [15]. To the best of our knowledge, the integration of satellite platform with RoFSO to produces high throughput transmission system also has been studied intensively [16]. The integration between optical fiber communications with wireless access technology also has been developed intensively as well. The integration between satellite communications with terrestrial platform also has been developed by NASA into deep space telecommunications system [17]. Even in the 5G technology, the integration of terahertz technology with visible light communication has been investigated intensively [18]. Also for mobile technology, the development of hybrid optical wireless vehicular for mobile access has been studied progressively [19]. The aforementioned results of development of hybrid communications technology has strong benefits such as avoiding the conversion of signal that causes systemto have delay latency, decreasing the interface of system to connecting two different of communications platform, and improving the rate transfer of data rate transmission.

In the integration between PON WDM of Palapa Ring and FSO, the ORN scheme is implemented as the bridge between the source and last destination of communication to reach the villages with high bandwidth. FSO as the ORN has many advantages which are no need line-of-sight path length, can reach the village in the order of tenth kilometers, the configuration can be setup into multi-path optical link which are composed of many nodes as the networks, can be setup to carrying WDM signals from PON of Palapa Ring, and the capacity is nearly the optical fiber rate transmission. FSO as the ORN has a major drawback which is the atmosphere as the medium of optical propagation [20]. Atmosphere is a medium that has characteristics of random process for the optical propagation where absorption, diffraction, and scattering goes in the fluctuation way causes phenomena which are so called as scintillation, spatio-temporal modulation and beam wandering [21]. Regarding this limitation, FSO as the ORN must be designed with an optical amplifier [22]. The implementation of an optical amplifier in the FSO brings benefits to penetrate the atmospheric turbulence thus the strength of the optical signal can be increased in significant to reach each node in the multi-path of optical link. Thus, the performance of hybrid optical communications that integrates PON WDM of the Palapa Ring network and FSO as the ORN can be emphasized in the best quality as the source does.

In this research, a scheme of hybrid optical communication that connecting PON WDM of the Palapa Ring network and FSO as the ORN is proposed as the solution to connecting the district and city with villages in the remote area. The capability of FSO as the ORN is setup to be multi-node transmission of optical link that is composed of many node (n-node). The PON is setup in the bandwidth transmission of 10 Gbps using single channel of WDM then the signal is forwarding by FSO-ORN in the scheme of multi-node configuration. In order to keep the optical signal robust from atmospheric turbulence, an optical amplifier is implemented for each node ensuring that the performance of communication system can be maintained between district and city to village. In order to improve the performance of system under turbulence effects, a novel technique to keep an optical signal remain high and low noise modulation, inline cascaded of optical amplifiers is implemented between node and optical band pass filter is applied before signal detection by photodetector. The main goal of this research is to investigate the performance of hybrid optical communication system between PON WDM and FSO in the scheme of ORN in penetrating the atmospheric turbulence. It is also as an effort to study the characteristics of an inline cascaded of optical amplifiers and implementation of optical band pass filter to support the total length of optical propagation under the influence of turbulence effects of atmosphere. Thus the contribution of this research through simulation under Optisystem 7.0 is finding a novel method to expand the optical propagation of FSO in several kilometers with the benefit of robust performance and high rate of data transmission as well.

This paper is organized into 4 chapters which are introduction section, detailing about potential of hybrid optical communication to be implemented in the Palapa Ring network as well as major problem to implement in this case. Second chapter is comprised of two sub-sections which are hybrid optical communications as the platform that combines optical fiber connection with FSO in the configuration of multi-node transmission as the sub-section 2.1 and simulation method to calculate the performance of systemas the sub-section 2.2. In chapter 3, results of simulation is explained in details with the parameters of performance in SNR and BER as the function of optical propagation path length for a signal under influence of atmospheric turbulence. Then, in chapter 4 , conclusion is emphasized in the configuration of optical fiber 
connection with the FSO as the hybrid optical communication that is supported by inline cascaded optical amplifiers and optical band pass filter as an optical signal amplification in ORN and a technique to minimize noise modulation in the receiver as well.

\section{RESEARCH METHOD}

In this section, the theory of hybrid optical communications that is composed of optical fiber and FSO communications is outlined. The optical fiber communications is the platform from The Palapa Ring Network, meanwhile FSO is the ORN to reach the remote area in the villages or rural area. Henceforth, the experimental setup through simulation is outlined as well.

\subsection{Fiber optics and free-space optical communication}

In order to support the Palapa Ring Network for connecting city and rural area with the capacity of high rate data transmission and high speed communications as well, hybrid optical communication is proposed as shown in Figure 2. Hybrid optical communication that is designed from transmitter (Tx) to receiver as end destination $(\mathrm{Rx})$ consist of optical fiber $(\mathrm{OF})$ connection and FSO. Commonly OF has span link distance in the order of tenth until hundreds even thous ands kilometers, in this proposed systemthe order of link distance is around tenth kilometers, remaining the averages distance of the Palapa Ring Network from a capital city of province to district. From city of district to reach rural areas, FSO has the main function to feed forward the information instead. In order to reach rural areas, FSO is designed in multi-node transmission where in the proposed system is performed by first- and second-node (OC-1 to OR-1 and OC-2 to OR-2).

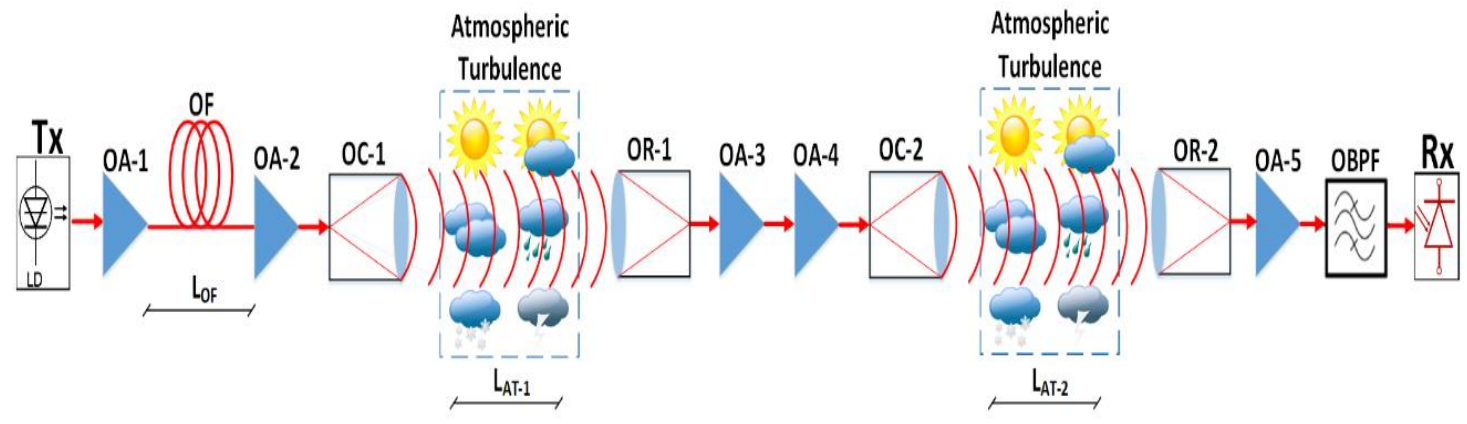

Figure 2. Proposed of hybrid optical communication to support the Palapa Ring Network in connecting city with the rural area where the FSO is designed in multi-nodes transmission

The optical signal from Tx is amplified by optical amplifier (OA-1) to be launched into OF in several kilometers (LoF). After propagating in OF, the optical signal is amplified by OA-2 to be transmitted out into atmospheric turbulence (AT-1) through FSO with the configuration of optical collimator and optical receiver (OC-1 and OR-1) as the first-node. Regarding turbulence media in atmospheric turbulence has characteristics of random attenuation and others optical phenomena along the path length of optical propagation ( $\mathrm{L}_{\mathrm{AT}-1}$ ), an optical signal is extremely attenuated as well as experience scintillation. Thus, an optical signal from the first-node need to be amplified in optimum. This amplification of optical signal is performed by inline cascaded of OA where in the proposed system is the serial configuration of OA-3 and OA-4. The output of serial configuration of OA is high intensity where ready to be transmitted out into atmospheric turbulence (AT-2) by OC-2 and OR-2 as the second-node. The optical signal from the second-node is very low intensity remaining the optical propagation under AT-2 as well. Thus, the optical signal need to be amplified by OA -5 where the output is coupled with optical band pass filter (OBPF) to reduce the noise modulation. The output of OA-5 and OBPF is high intensity with low noise of modulation. Then the optical signal arrives at photodetector as the receiver (Rx) to be detected and transformed into an electrical signal or data rate.

Based on the streaming process of optical signal from Tx to Rx as has been outlined in the previous, the received of optical power in the Rx for the condition of static atmospheric turbulence where only attenuation effect induces the optical propagation, $P_{R x}^{0}$ is given as [23], 


$$
P_{R x}^{0} \approx P_{T x}-L_{O F} \alpha_{O F}-L \alpha_{A T}+\sum_{1}^{n} P_{O A}-\sum_{1}^{m} \eta_{l o s s}
$$

where $P_{T X}$ is the output of signal power from laser transmitter, $P_{O A}$ is the output of signal power from each OA, $n$ is the number of OA, $L_{O F}$ is the length span of optical fiber, $\alpha_{O F}$ is the attenuation factor of optical fiber, $L$ is the total path length of optical propagation under atmospheric turbulence (AT-1 and AT-2), $\alpha_{A T}$ is the attenuation factor of atmospheric turbulence, $\eta_{l o s s}$ is the parameter for coupling loss and filter loss, and $m$ is the number of coupling in the proposed system of hybrid optical communication. $\alpha_{A T}$ is stated as [24],

$$
\alpha_{A T} \cong 2 \sqrt{23.17 k^{6 / 7} C_{n}^{2} L^{11 / 6}}
$$

where $k=2 \pi / \lambda$ is the wavelength number and $C_{n}^{2}$ is the index of structure whereas the variable of turbulence scale. Under atmospheric turbulence effects, the received signal of optical power in the pupil plane of receiver is stated in Eq. (3) [25-26],

$$
\left\langle P_{R x}\right\rangle=\frac{1}{8} \pi D_{G}^{2}\left\langle I_{0, L_{A T-2}}^{0}\right\rangle \cong \frac{\pi D_{G}^{2}\left\langle I_{0, L_{A T-2}}^{0}\right\rangle}{8\left(1+1.63 \alpha_{A T}{ }^{12} / 5 \Lambda_{1}\right)}
$$

where $\langle$.$\rangle denotes the mean value, D_{G}$ is hard diameter of receiver lens in OR-2, $I_{0, L_{A T-2}}^{0}$ is the intensity of collimated optical propagation by OC-2 to reach pupil plane of OC-1 in the absence of atmospheric turbulence and $\Lambda_{1}$ is the effective of aperture radius where received in the pupil plane of OR-2 as well. Thus, the performance of signal-to-noise ratio (SNR) are given by [26],

$$
\langle S N R\rangle \cong \frac{S N R^{0}}{\left(\frac{P_{R x}^{0}}{\left\langle P_{R x}\right\rangle}+\sigma_{I}^{2}\left(D_{G}\right)\left(S N R^{0}\right)^{2}\right)^{\frac{1}{2}}}
$$

where $\sigma_{I}^{2}$ is the irradiance flux variance in the photodetector of $\mathrm{Rx}$. Henceforth, the performance of bit-error-rate (BER) which based on value of $\langle S N R\rangle$, also by assmuming the signal is OOK (on-off keying) and the distribution of signal intensity under turbulence effects is gamma-gamma, $\langle B E R\rangle$ is stated as [25],

$$
\langle B E R\rangle \cong \frac{1}{2} \int_{0}^{\infty} p_{I}(u) \operatorname{erfc}\left(\frac{\langle S N R\rangle u}{2 \sqrt{2}}\right) d u
$$

where $p_{I}(u)$ is the PDF (probability of density function) of gamma-gamma with unity means for irradiance fluctuations.

\subsection{Setup of simulation}

Setup of simulation under Optisystem 7.0 is shown in Figure 3, where the integration between optical fiber communication (OFC) system and FSO are described by each main component or unit. The OFC operates from laser transmitter Tx where the output is coupled into modulator which is Mach-Zender interferometer (MZI). The output light from Tx is modulated with the electrical signal from pseudo random bit sequence generator(PRBS) thus this scheme produces an optical signal that is launched into optical fiber (OF). Before the optical signal is launched into OF, an optical amplifier (OA-1) amplifying the optical signal into high intensity. The output from OA-1 then launched into OF with propagation path length several kilometers (LoFC) as to reach the FSO system that is consist of optical forward relaying network. The output from OF, the optical signal is amplified with OA-2 then coupled into optical collimator (OC-1) to produce a beam light or optical propagation that is transmitted into atmospheric turbulence. The optical propagation from OC-1 penetrates the atmos pheric turbulence in the path length of $\mathrm{L}_{\mathrm{AT}-1}(\mathrm{~km})$. After then, the optical signal is received by an optical receiver (OR-1) as the forward relaying network into OC-3. Before the signal is launched into atmospheric turbulence in the path length of $\mathrm{LAT}_{\mathrm{A}-2}(\mathrm{~km})$, an inline cascaded optical amplifiers which are OA-3 and OA-4 amplifies the optical signal into high intensity. The output from OA-3 and OA-4 is collimated as an optical propagation by OC-2 and launches the optical propagation into atmospheric turbulence to reach OR-2. 
The output of OR-2 is coupled into OA-5 to produce an optical signal with high intensity. The output from OA-5 is filtered by optical band pass filter (OBPF) the result is received by photodetector of PIN (Rx). The measurement point of performance is located in the $\mathrm{Rx}$ where the optical signal is coupled into optical spectrum analyzer (OSA) and optical power meter (PM) while the quality of signal is measured from the output of $\mathrm{Rx}$ with the BER-tester instrument.

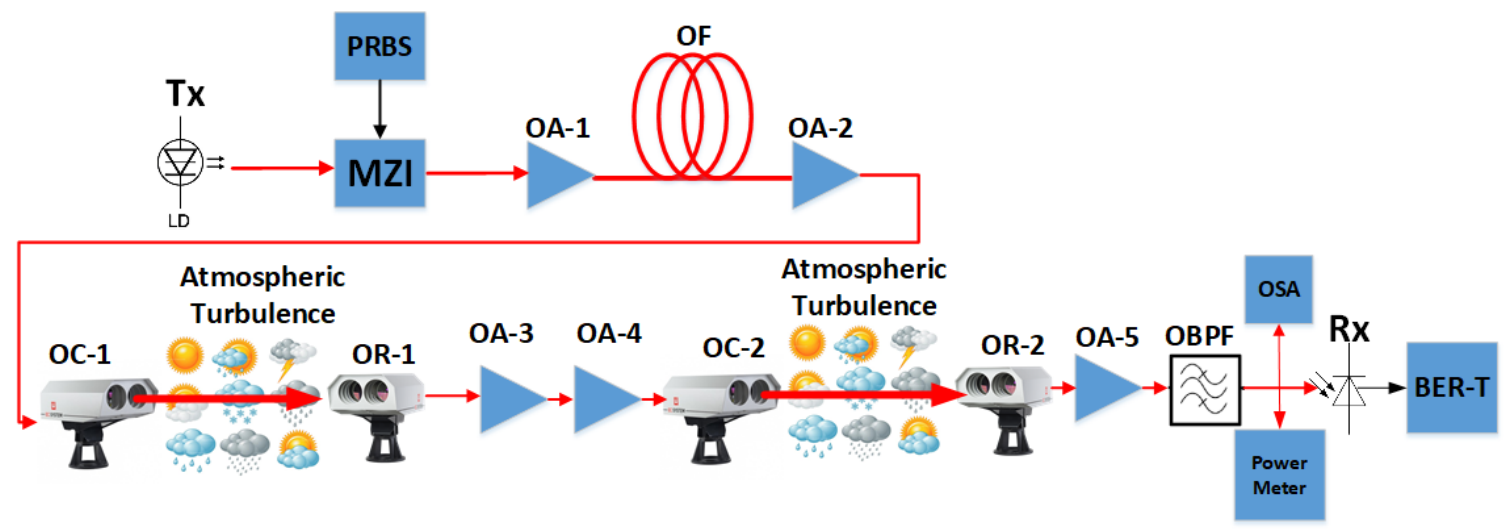

Figure 3. The simulation setup for hybrid optical communications that consist of optical fiber communications systemintegrated with FSO in the configuration of forwarded ORN or so called as FSO-ORN

Figure 3 is the setup configuration of hybrid optical communication for simulation under Optisystem 7.0. The parameters of simulation for OFC and FSO systems is shown in Table 1, where each component is described with value or type. All of the optical amplifiers that are used in the simulation implement Erbium-doped fiber amplifier (EDFA) as the scheme of optical signal amplification process after the signal is attenuated by $\mathrm{OF}$ or atmospheric turbulences between OC-1 to OR-1 and OC-2 to OR-2. All of the parameters in OFC and FSO are typical values that eventually used in the real environment of optical link budget as in example the power of laser transmitter $\mathrm{P}_{\mathrm{Tx}}$ is usually $0 \mathrm{dBm}$.

Table 1. The parameters from OF and FSO that used in the simulation in Optisytem 7.0

\begin{tabular}{|c|c|}
\hline \multicolumn{2}{|r|}{ Optical fiber communications system } \\
\hline $\mathrm{Tx}$ & $\begin{array}{l}\lambda=1552.52 \mathrm{~nm} \\
-\mathrm{P}_{\mathrm{Tx}}=0 \mathrm{dBm}\end{array}$ \\
\hline PRBS & $\begin{array}{l}\text { - Sequence type of signal is random } \\
\text { - } 10 \mathrm{Gbps}\end{array}$ \\
\hline MZI & Modulation type is NRZ (non-return to zero) \\
\hline $\mathrm{OF}$ & $\begin{array}{l}\text { - Single mode fiber } \\
\text { - Attenuation }=0.2 \mathrm{~dB} / \mathrm{km}\end{array}$ \\
\hline OA-1 & EDFA, $\mathrm{P}_{\mathrm{OA}-1}=10 \mathrm{dBm}$ \\
\hline $\mathrm{OA}-2$ & EDFA, $\mathrm{P}_{\mathrm{OA}-2}=25 \mathrm{dBm}$ \\
\hline \multicolumn{2}{|r|}{ Free-space optical communications system } \\
\hline OC-1 \& OC-2 & Collimation aperture diameter $=5 \mathrm{~cm}$ \\
\hline OR-1 \& OR-2 & Receiver aperture diameter $=20 \mathrm{~cm}$ \\
\hline OA-3 & EDFA, $\mathrm{P}_{\mathrm{OA}-3}=25 \mathrm{dBm}$ \\
\hline OA-4 & $\mathrm{EDFA}, \mathrm{P}_{\mathrm{OA}-4}=25 \mathrm{dBm}$ \\
\hline OA-5 & EDFA, $P_{O A-5}=25 \mathrm{dBm}$ \\
\hline $\mathrm{OPBF}$ & $\begin{array}{l}\text { - Gaussian optical filter } \\
\text { - Center frequency is } 193.1 \mathrm{THz} \\
\text { - Bandwidth } 50 \mathrm{GHz}\end{array}$ \\
\hline $\mathrm{Rx}$ & $\begin{array}{l}\text { - PIN photodiode } \\
\text { - Responsivity =1 A/W }\end{array}$ \\
\hline
\end{tabular}

In the simulation, the attenuation for atmospheric turbulences is setup to be static with regards to Rytov formula as the index of structure. Since the optical propagation path length in atmospheric turbulence for OC-1 to OR-1 and OC-2 to OR-2 is relatively in the same conditions of weather, the index structure of atmosphere can be assumed uniform. Thus in the simulation the attenuation factor is set in $10 \mathrm{~dB} / \mathrm{km}$. 
The variables in the simulation are set for LoFC, LAT-1 and LAT-2 where each of them represents the path length of optical propagation in optical fiber, atmospheric turbulences for OC-1 to OR-1 and OC-2 to OR-2, respectively.

\section{RESULTS AND DISCUSSION}

The results of simulation are shown in Figures 4 and 5, where the LoF is set to be constant at $75 \mathrm{~km}$ meanwhile LAT-1 and LAT-2 are set to be various with the total length of optical propagation in the atmospheric turbulences is $L=L_{A T-1}+L_{A T-2}$. Those total length of optical propagation is ranging from 1 to $9.4 \mathrm{~km}$. LoF is set to be constant, by considering that the moderate distance between cities of district with rural area in Indonesia is about $75 \mathrm{~km}$.

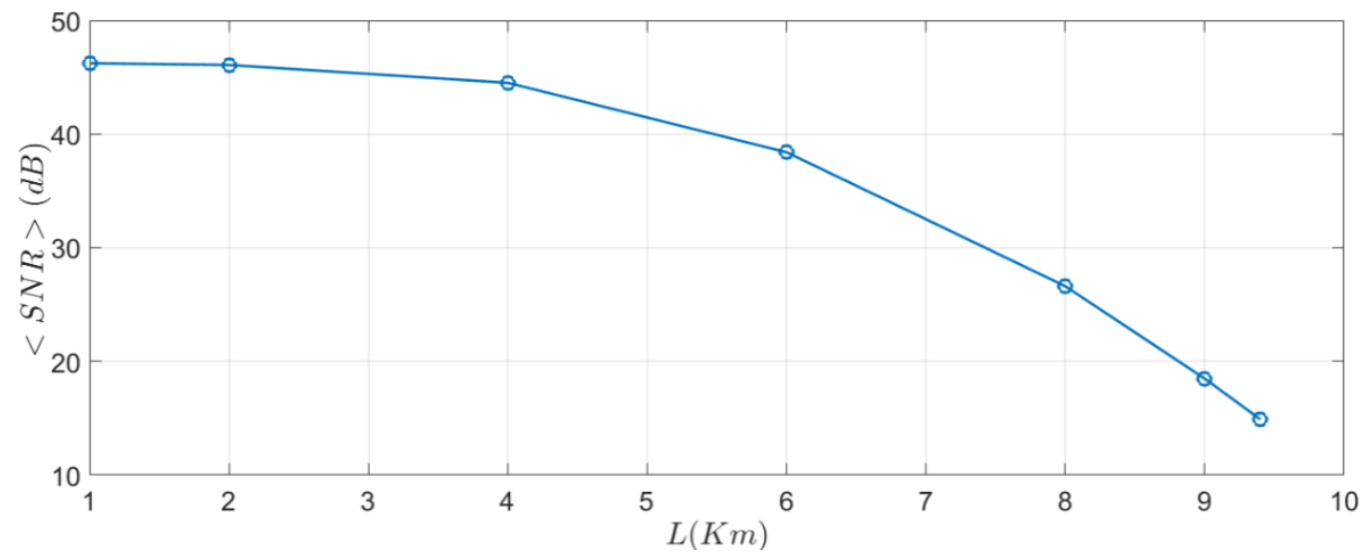

Figure 4. The $\langle S N R\rangle$ performance of hybrid optical communication where the length span of optical fiber set to be constant at $75 \mathrm{~km}$, while the optical propagation under atmospheric turbulence in AT-1 and AT-2 are set to be various

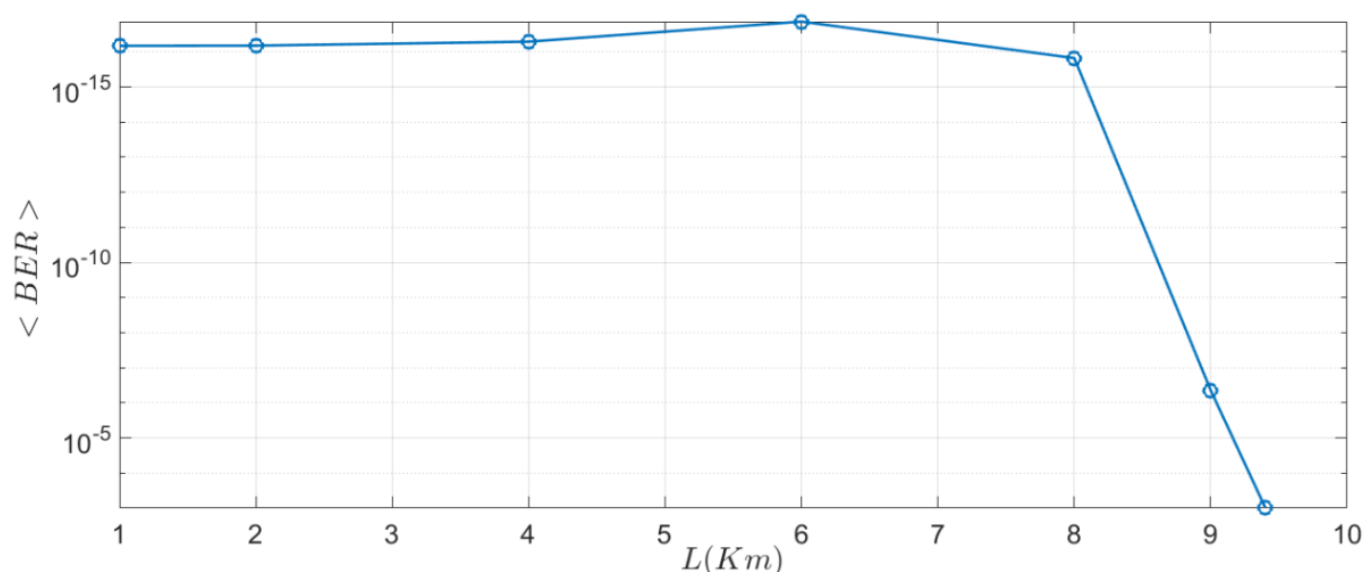

Figure 5. The $\langle B E R\rangle$ performance of hybrid optical communication where the length span of optical fiber set to be constant at $75 \mathrm{~km}$, while the optical propagation under atmospheric turbulence in AT-1 and AT-2 are set to be various

Meanwhile, from the measurement where OA-4 and OBPF are removed from the simulation setup or non-inline cascaded configuration of OA, for all L, the performance of system is in worst quality. As an example, at $\mathrm{L}=8 \mathrm{~km}$ the value of $\langle S N R\rangle$ is $-36.75 \mathrm{~dB}$ and $\langle B E R\rangle$ is 1 , means that the signal is dominated by noise in the Rx. Also, by implementing inline cascaded of OA where OBPF is removed before the optical signal goes to $\mathrm{Rx}$, the performance of system also degrades in optimal where at $\mathrm{L}=8 \mathrm{~km}$ the value of $S N R$ and $\langle B E R\rangle$ are $-11.78 \mathrm{~dB}$ and 1 as well. Hence, the novel technique that is implemented in 
hybrid optical communication system gives improvement for the performance and the range distance of optical propagation that can be achieved also more longer as outlined in the below paragraph.

Based on the results of simulation as shown in Figs. 4 and 5, it can be seen that the performance of OFC and FSO for LoF=75 km, quality of SNR and BER values decrease as the total length of optical propagation in the atmospheric turbulences between OC-1 to OR-1 and OC-2 to OR-2 increases. The maximum quality values for SNR and BER are achieved at $L=1.0 \mathrm{~km}$, meanwhile the minimum of ones are achieved at $L=9.4 \mathrm{~km}$. It can be seen also that the configuration of OFC and FSO in the simulation, tend to robust at the range of $L$ in 1.0 to $8 \mathrm{~km}$, but after that distance the performance degrades to worst quality. Thus, for $L$ in 8 to $10 \mathrm{~km}$ is the critical points where ORN cannot forwarded the optical signal more longer in the atmospheric turbulence. The optical signal in OF is maintained in high intensity by OA-1 and OA-2, thus the quality is quite high as the source from Tx. But when the optical signal goes through atmospheric turbulence it will degrade optimally caused by atmospheric turbulence effects. For this reason, the output of optical propagation from OC-1 is kept high with the amplification from OA-2 to penetrate the atmospheric turbulence into OR-1. However, the optical propagation is optimally induced by atmospheric turbulence and maintained high gain of signal by the configuration of cascaded EDFA's (OA -3 and OA-4). This configuration of OC-1 to OR-1 and OC-2 and OR-2 acts as the forward ORN, thus in order the optical propagation capable to penetrate the second atmospheric turbulence stages, the output of optical signal from OA-3 and OA-4 is high intensity to reach OR-2. The output of optical signal from OR-2 then is amplified by OA-5 in order to keep high intensity as well. Nonetheless, even the optical signal is high intensity from OA-5, noise modulation is also major is sue to be resolved with OBPF with the type filtering in Gaussian and the bandwidth of $50 \mathrm{GHz}$. Thus the optical signal after propagates in the atmos pheric turbulences is minimum from noise modulation.

The comparis on of signal spectrum characteristics from OFC and FSO are shown in Figures 6 and 7. In Figure 6(a), the signal spectrum as the result of optical propagation on OF only get attenuation process along $75 \mathrm{~km}$ fiber span. Thus, the optical signal relatively modulates noise in minimum, as shown by profile of eyediagram. The pattern of eyediagram shows relatively signal transition little bit clearly rather. But this situation drastically changing when the optical signal propagates along the atmospheric turbulence as shown in Figure 7(a). The characteristics of optical signal spectrum on the FSO degrades optimally caused by turbulence effects along the propagation path length at $L=9.4 \mathrm{~km}$. This condition is justified by the profile of eyediagram on Figure 7(b), that the noisy of signal as indicated by blue line, shows the transition of signal between " 0 " and " 1 " is not clear as the result of signal from OFC as can be seen in Figure 6(b). Thus the Q-factor in OFC is higher as indicated by red line in Fig. 6(b) than the value in Figure 7(b). It is clear evidence that the signal spectrum modulates noise in higher than signal at OFC system Thus, the performance of FSO also degrades as well. As comparison the performance of OFC is produced at $\langle S N R\rangle=47.78 \mathrm{~dB}$ and $\langle B E R\rangle=1.7 \times 10^{-13}$. Meanwhile the performance of FSO is produced at $\langle S N R\rangle=18.48 \mathrm{~dB}$ and $\langle B E R\rangle=4.47 \times 10^{-7}$. For this reas on a scheme to enhance the performance for hybrid optical communications should be seriously taken into account.

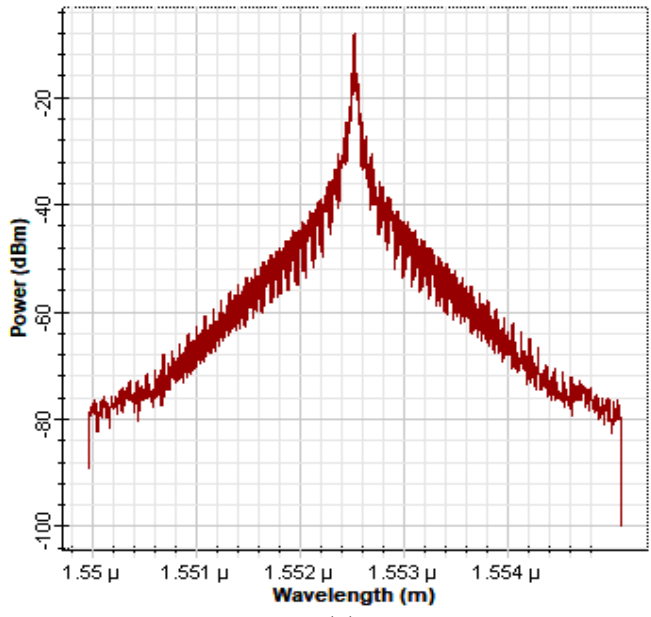

(a)

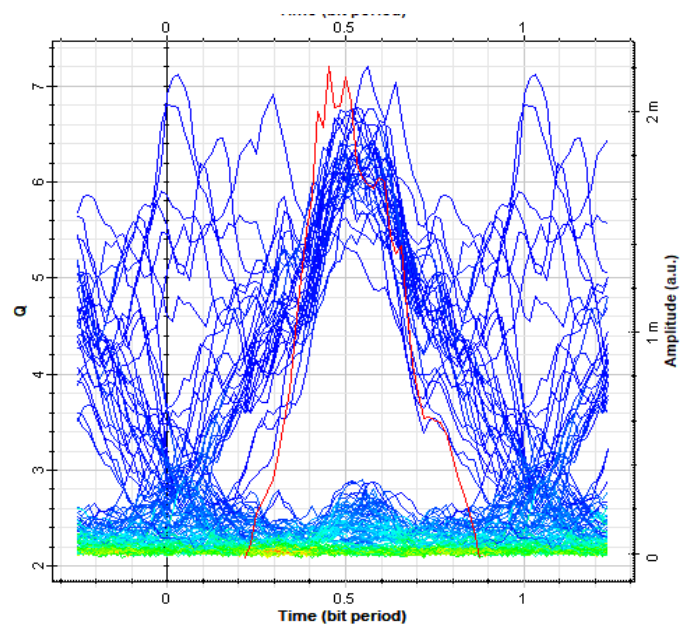

(b)

Figure 6. The characteristics of signal spectrum and eyediagram of signal under OFC systemat $\mathrm{L}_{\mathrm{OF}}=75$ $\mathrm{km}$, (a) Optical signal spectrum at $1552.52 \mathrm{~nm}$, (b) Eyediagram of signal from the receiver 


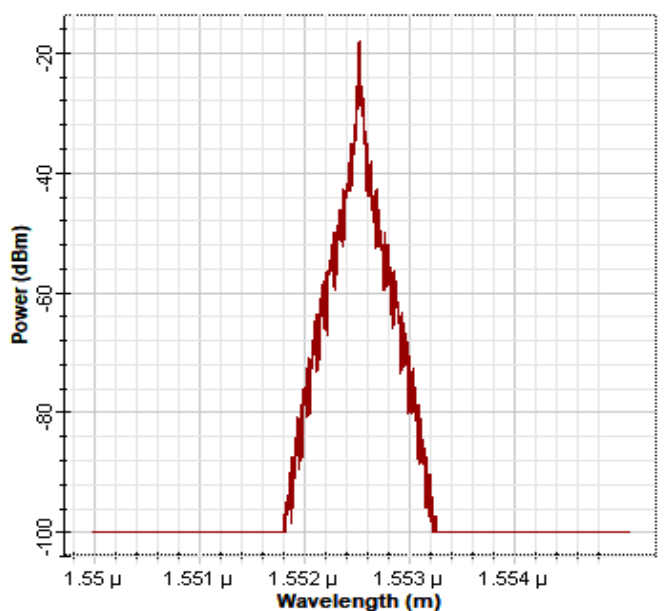

(a)

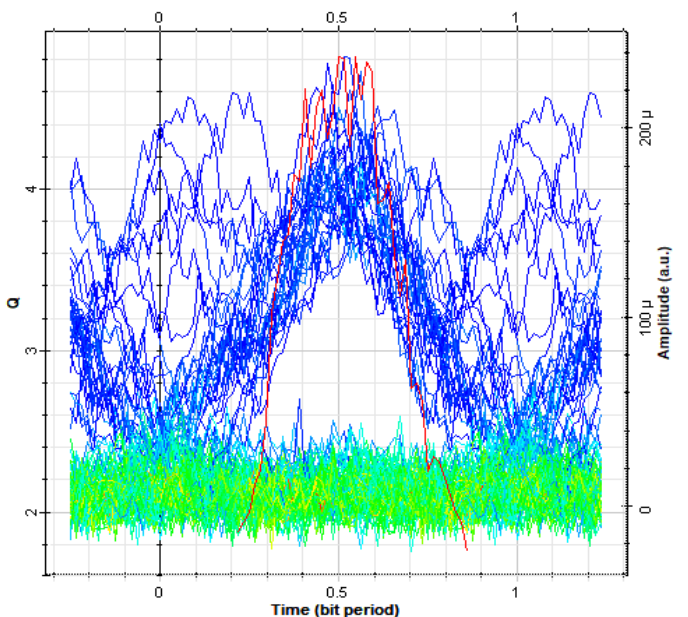

(b)

Figure 7. The characteristics of signal spectrum and eyediagram of signal under FSO system at $L=9.4 \mathrm{~km}$, (a) Optical signal spectrum at $1552.52 \mathrm{~nm}$, (b) Eyediagram of signal from the receiver

To better understand the important for implementing OBPF in the output of OA-5 before the optical signal is directed into $\mathrm{Rx}$, is shown by Figure 8. The eyediag ram in Figure 8 (a) is $\langle S N R\rangle$ and $\langle B E R\rangle$ measurement at $L=6 \mathrm{~m}$. The values of $\langle S N R\rangle$ and $\langle B E R\rangle$ for using OBPF are $38.46 \mathrm{~dB}$ and $\langle B E R\rangle=1.37 \times 10^{-17}$, respectively. Meanwhile for not using OBPF as shown in Figure 8(b), the values of $\langle S N R\rangle$ and $\langle B E R\rangle$ are $37.23 \mathrm{~dB}$ and $2.17 \times 10^{-13}$, respectively. Regarding some samples of eyediagram as shown in Figure 8(a) and (b), it can be inferred that the OBPF performs filtering to the result of optical signal amplification from OA-5 that has a possibility of high noise from modulation of atmospheric turbulence that goes to the amplification process in EDFA. In Figure 8(a), the transition of signal between "0" (low state) and " 1 " (high state) during time period of bit is very smooth and clear as well minimum from noise fluctuations as indicated by blue line. Meanwhile in Figure 8(b), the transition of signal between low state and high state somewhat has noisy characteristics as indicated by blue line as well. Thus, the value of SNR and BER is achieved higher through the implementation of OBPF as indicated by Q factor which is red line in Figure 8(a). Meanwhile, the value of SNR and BER is achieved lower for non-OBPF at Rx as indicated by Q factor which is red line in Figure 8(b). Another function of OBPF is also filtering the wide bandwidth of optical signal that is produced by EDFA that has typical characteristics of $40 \mathrm{~nm}$. Thus, OBPF produces the optical signal with minimum of noise modulation as shown by the comparison of eyediagram in Figure 8(a) and 8(b).

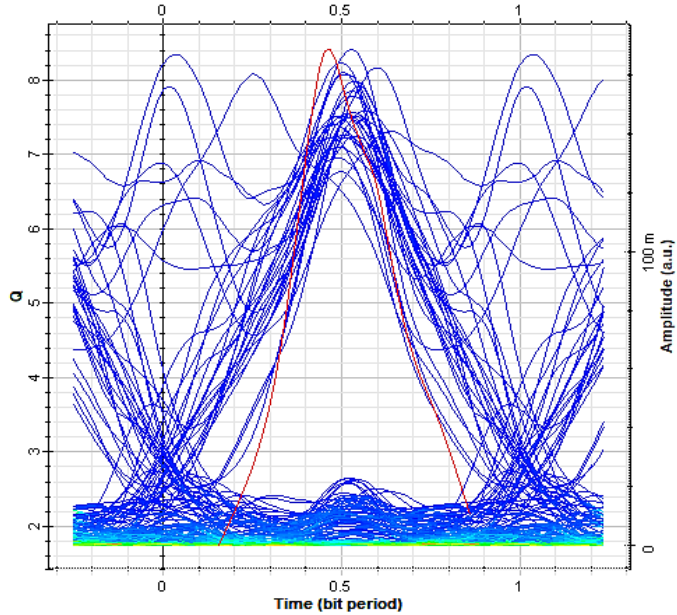

(a)

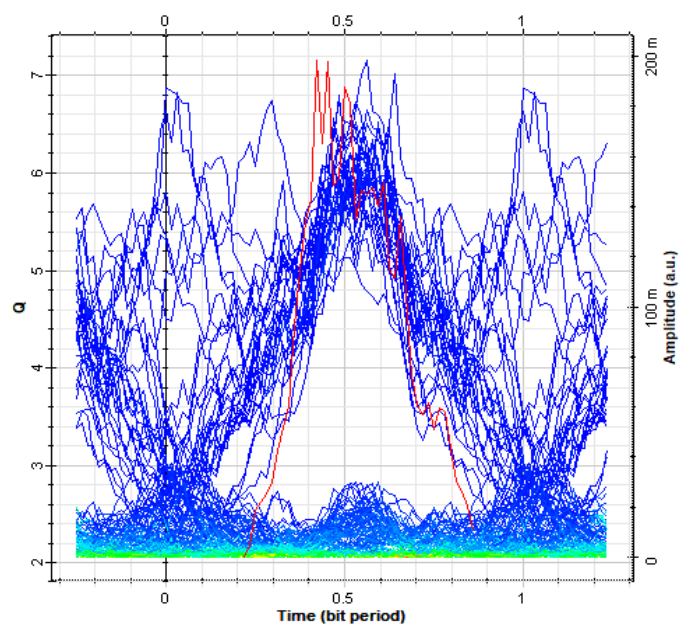

(b)

Figure 8. The profile of eyediagram comparis on from the output of OA-5 before the optical signal is received by Rx in the second node, (a) Using OBPF, (b) Not using OBPF 
Regarding the results of simulation as shown in Figures $4-8$, a scheme to enhance the performance of hybrid optical communication should consider the different characteristics for medium of optical propagation. OF is the perfect medium relatively for an optical signal to propagate along the length span in tenth or hundred even thousand kilometers. The optical signal on OF relatively modulates noise in minimum since the optical phenomena inside does not behave random. Thus, OFC produces good performance remaining the optical signal is maintained high by the implementation of OA-1 as shown in Figure 3. Atmospheric turbulence as the optical propagation for FSO is quite different. Atmosphere modulates its turbulence effect on optical propagation that fluctuates in space and time or behaves random fashion. For this reason, in order to keep the performance as high as in OFC, in FSO, the implementation of optical amplifiers before the optical signal is transmitted out into atmospheric turbulence as well as after then propagates along is mandatory for hybrid optical communications. Nonetheless, even the implementation of optical amp lifiers can maintain high gain of signal along the propagation path length under atmospheric turbulence, the problem of noise modulation in the end of signal reception of $\mathrm{Rx}$ still does exist. Those, in the simulation, the implementation of OBPF that capable to suppress noise modulation is also mandatory for hybrid optical communication. The main function of installing OBPF in the end of signal reception is to suppress the bandwidth noise that accumulates in optical propagation after optical signal goes through along several kilometers in atmospheric turbulence. The overall signal output from inline cascaded configuration of optical amplifiers gather with OBPF produces high gain and minimum from noise modulation instead. Thus, by the scheme of implementing optical amplifiers and OBPF in Rx for hybrid optical communication can leverage the performance of overall systemover length span of optical propagation in each node of ORN.

This limitation of the simulation of hybrid optical communication under Optisystem 7.0 is the assumption of atmospheric turbulence level that is not set has variation with time. In the simulation turbulence level is set to be constant at $10 \mathrm{~dB}$ since in the range of $10 \mathrm{~km}$, the strong turbulence level is under this value based on Rytov formula. In nature, turbulence level has variation with time even dynamic fluctuation. Thus, this condition is a challenge for future research to propose an approximation of performance measurements based on dynamic condition of the atmospheric turbulence.

\section{CONCLUSION}

The major motivation of this research is finding a novel technique to expand the link distance of optical network between optical fiber communication and free-space optical communications as well as to improve the performance. The hybrid of optical communication that is consist of optical fiber communication and free-space optical communications in the configuration of ORN has been successfully designed through the implementation of novel technique where inline cascaded optical amplifiers is used in the node of transmission and the result of optical signal amplification by single EDFA in optical receiver near Rx is filtered by optical band pass filter. The configuration of OFC and FSO with novel technique as outlined in previous section has significant result where total length of optical propagation in the atmospheric turbulence that can be achieved in the simulation is $1-8 \mathrm{~km}$ with the length of optical fiber is constant at $75 \mathrm{~km}$. This significant result is proved by the performance in SNR and BER where range values are 46.23-26.61 dB and $6.7 \times 10^{-17}-1.5 \times 10^{-6}$. The length of optical fiber represents the distance of PON WDM in Palapa Ring network that commonly exist in the district or city. Thus to forward ing the internet in backbone to reach villages or rural area, FSO in the configuration of the ORN can be implemented to integrating the platform of all optical signals transmission through the Palapa Ring network.

\section{ACKNOWLEDGEMENTS}

The authors would like to give appreciation and thank for the Research Grant of Hibah Pasca Doktor in the years of 2018-2019 from Kemristekdikti. Also the contributions from Dr. Retno Wigajatri and Mr. Surma in Laboratory of Opto-Electrotechnique and Laser Applications in Universitas Indonesia for providing the facility of research.

\section{REFERENCES}

[1] D. Setiawan and N. R. Fahrurrozi, "Feasibility analysis with capital budgeting backbone network fiber optic cable west palapa ring," International Conference on Broadband Communication, Wireless Sensors and Powering $(B C W S P)$, pp. 1-4, 2017.

[2] M. N. D. Satria and S. Haryadi, "Effect of the content store size to the performance of named data networking: Case study on Palapa Ring topology," 11th International Conference on Telecommunication Systems Services and Applications (TSSA), pp. 1-5, 2017.

[3] M. N. D. Satria, F. H. Ilma and N. R. Sy ambas, "Performance comparison of named data networking and IP-based networking in palapa ring network," 3rd In.Conference on Wireless and Telematics (ICWT), pp. 43-48, 2017.

[4] Sy awaldipa and S. Hary adi, "Packet drop analy sis on NDN's content distribution, case study: Palapa ring topology," $3 r d$ International Conference on Wireless and Telematics (ICWT), pp. 195-199, 2017. 
[5] S. Ahdan, H. Situmorang, and N. R. Sy ambas, "Forwarding strategy performance in NDN network: A case study of palaparing topology,"3rd International Conference on Wireless and Telematics (ICWT), pp. 20-25, 2017.

[6] T. Adiguna, Hendrawan, and H. Nusantara, "East Nusa Tenggara submarine cable communication sy stem design," 3rd International Conference on Wireless and Telematics (ICWT), pp. 70-75, 2017.

[7] F. Kasmar and S. Hary adi, "Delay analysis on load balancing NDN, case study: Palapa ring," 3rd International Conference on Wireless and Telematics (ICWT), pp. 186-190, 2017.

[8] U. Darusalam, P. S. Priambodo, E. T. Rahardjo, "SNR and BER performance enhancement on FSO induced by atmospheric turbulence using optical spatial filter," Int. J.of Optics and Applications, vol. 5, no. 3, pp. 51-57, 2015.

[9] B. Patnaik and P. K. Sahu, "optimized hybrid optical communication system for first mile and last mile problem solution of today's optical network," Procedia Technology, vol. 6, pp. 723-730, 2012.

[10] H. Dahrouj, A. Douik, F. Rayal, T. Y. Al-Naffouri, and M. S. Alouini, "Cost-effective hybrid RF/FSO backhaul solution for next generation wireless systems," IEEE Wireless Communications, vol. 22, no. 5, pp. 98-104, 2015.

[11] Z. Ghassemlooy, S. Arnon, M. Uysal, Z. Xu, and J. Cheng,."Emerging optical wireless communications-advances and challenges," IEEE journal on selected areas in communications, vol. 33, no. 9, pp. 1738-1749, 2015.

[12] Z. Huang, Z. Wang, M. Huang,W. Li, T. Lin, P. He, and Y. Ji, "Hybrid optical wireless network for future SAGO-integrated communication based on FSO/VLC heterogeneous interconnection," IEEE Photonics Journal, vol. 9, no. 2, pp. 1-10, 2017.

[13] P. Sarigiannidis, T. Lagkas, S. Bibi, A. Ampatzoglou, and P. Bellavista, "Hybrid 5G optical-wireless SDN-based networks, challenges and open issues," IET Networks;vol. 6, no. 6, pp. 141-148, 2017.

[14] A. Tzanakaki et al., "Wireless-optical network convergence: Enabling the 5G architecture to support operational and end-user services," IEEE Communications Magazine, vol. 55, no. 10, pp. 184-192, 2017.

[15] M. N. Khan and M. Jamil, "Adaptive hybrid free space optical/radio frequency communication system," Telecommunication Systems, vol. 65, no. 1, pp. 17-26, 2017.

[16] D. M. Cornwell, "NASA's optical communications program for 2017 and beyond," IEEE International Conference on Space Optical Systems and Applications (ICSOS), pp. 10-14, 2017.

[17] D. R. Kolev and M. Toy oshima, "Transmission analy sis for OFDM signals over hy brid RF-optical high-throughput satellite," Optics Express, vol. 26, no. 4, pp.4942-4953, 2018.

[18] S. E. Alavi, M. R. Soltanian. I. S. Amiri. M. Khalilv. A. S. Supa'At. and H. Ahmad. "Towards 5G: A photonic based millimeter wave signal generation for applying in 5G access fronthaul," Scientific Reports, vol. 6, no. 19891, pp. 1-11, 2016

[19] B. Li, W. Xu, H. Zhang, C. Zhao, and L. Hanzo, "PAPR reduction for hybrid ACO-OFDM aided IM/DD optical wireless vehicular communications," IEEE Trans. on Vehicular Technology, vol. 66, no. 10, pp.9561-9566, 2017.

[20] P. V. Trinh, N. T. Dang, and A. T. Pham, "All-optical relaying FSO systems using EDFA combined with optical hard-limiter over atmospheric turbulence channels," J. of Lightw. Tech., vol. 33, no. 19, pp. 4132-4144, 2015.

[21] U. Darusalam, P. S. Priambodo, and E. T. Rahardjo, "Optical spatial filter to suppress beam wander and spatial noise induced by atmospheric turbulence in free-space optical communications," Advances in Optical Technologies, 2015.

[22] E. Bay aki, D. S. Michalopoulos, and R. Schober, "EDFA-based all-optical relay ing in free-space optical sy stems," IEEE Transactions on Communications, vol. 60, no. 12, pp.3797-3807, 2012.

[23] L. C. Andrews and R. L. Phillips, "Laser beam propagation through random media (vol. 152)," Bellingham, WA: SPIE Press, 2005.

[24] U. Darusalam, P. S. Priambodo, and E. T. Rahardjo, "Optical spatial filter to suppress beam wander and spatial noise induced by atmospheric turbulence in free-space optical communications," Advances in Optical Technologies, pp. 1-6, 2015.

[25] U. Darusalam, P. S. Priambodo, and E. T. Rahardjo, "SNR and BER performance enhancement on FSO induced by atmospheric turbulence using optical spatial filter," Int. J. of Optics and Applications, vol. 5, no. 3, pp. 51-57, 2015.

[26] I. Toselli, L. C. Andrews, R. L. Phillips, and V. Ferrero, 2008. "Free-space optical sy stem performance for laser beam propagation through non-Kolmogorov turbulence," Optical Engineering, vol. 47, no. 2, pp. 1-11, 2008.

\section{BIOGRAPHIES OF AUTHORS}

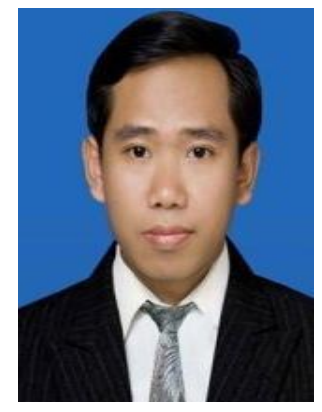

Ucuk Darusalam was born in Pacet Village, Mojokerto on 27 April 1979. He received Bachelor Engineering from Institut Teknologi Sepuluh November (ITS) in 2002, majoring in Photonics Engineering. In 2008, he received Master of Engineering from Faculty of Engineering, Universitas Indonesia, majoring in Opto-Electrotechnique and Laser Applications. In 2015, he also received Doctor of Engineering degree from Faculty of Engineering, Universitas Indonesia, majoring in Opto-Electrotechnique and Laser Applications. During doctoral research in Universitas Indonesia, he conducted research in Chiba University of Japan in 2013. During $2018-2019 \mathrm{He}$ also conducted Post Doctoral research in Laboratory of Opto-Electrotechnique and Laser Applications, Department of Electrical Engineering, Universitas Indonesia. Currently, he is a lecturer in Universitas Nasional, Jakarta. He is right now Dean of ICT Faculty Universitas Nasional . His research interests are photonics engineering, optical fiber communications, optical signal processing, digital hologram, free-space optical communications, optical and computer network, data \& network communications and Li-Fi for computer network. He is also member of IEEE in the Photonics Society. During 2018-2019, he was appointed as the vice chair of IEEE Indonesia section. Currently, he is now being appointed as the Chair of Membership Committee. 


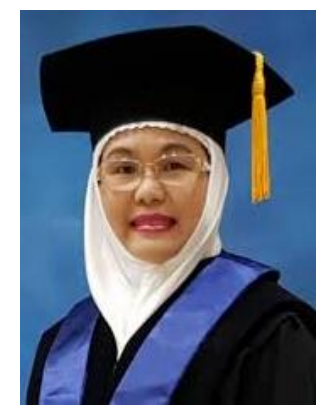

Fitri Yuli Zulkifli is a Professor in the Electrical Engineering Department, Faculty of Engineering, Universitas Indonesia. She received her Bachelor and $\mathrm{PhD}$ (cum laude) degrees in Telecommunications Engineering from Universitas Indonesia and $\mathrm{MSc}$ degree in Telecommunication and Information Technology Department, University of Karlsruhe, Germany. Her research interests are Antenna, Propagation, Microwave and in the field of Electromagnetic. She joined the Antenna Propagation and Microwave Research Group (AMRG) UI since 1997 and has become lecturer since 1998 . She has published more than 100 papers in international/national journals and conference proceedings and has been involved in more than 31 granted researches. In 2011 she was granted "Dosen Berprestasi UI" and achieved 4th place "Dosen Berprestasi tingkat nasional". She is involved in many teamwork activity in UI like for BAN, PHKI, QUE, AUN and also involved as organizing committee in many seminars and workshops. Fitri Yuli Zulkifli in 2009 has been the Secretary and Treasurer of IEEE joint chapter MTT/AP, and in 2010 as Treasurer of the same joint chapter, than from 2011-2012 she has become the joint chapter chair. As joint chapter chair, she has encouraged students to form Student Branch of MTT-S and Student Branch of AP-S at Universitas Indonesia. Now she conducts as coordinator technical activity in IEEE Indonesia section as well as executive committee of joint chapter MTT/AP-S. She has organized the inaugural National Symposium on Microwave, Antennas and Propagation 2012 in 3 October 2012. This event is focused on MTT/AP society members to actively get involved in technical activities and to be recognized by people who are working as academic staffs, researchers, government officials, industry professionals and students as well. Moreover she has participated as committee in many scientific symposiums. She is also member of the International Steering Committee for APMC (Asia Pacific Microwave Conference since 2010) and ISAP (International Symposium on Antenna and Propagation since 2012).

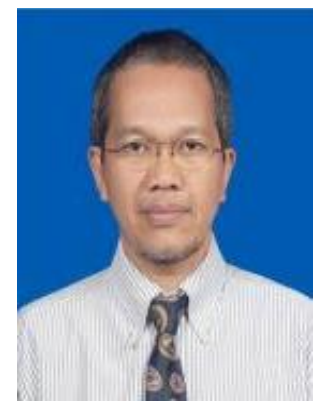

Purnomo Sidi Priambodo received his Bachelor of Science degree in Electrical Engineering from Gadjah Mada University, Indonesia, in 1987. From 1987 to 1994, he joined PT Indosat. His job experiences spread out from satellite earth station to data communication and sy stem programmer. In 1995, he went to US to pursue Master of Science, and received it from School of Electrical and Computer Engineering, Oklahoma State University at Stillwater in 1996. In 1997, he transferred to Department of Electrical Engineering at the University of Texas at Arlington to pursue a Doctoral degree in Photonics and diffractive optics. He received PhD degree in 2003. During 2003-2005, He was a postdoctoral fellow at UT Arlington and a senior research scientist at Resonant Sensors Incorporated. He has a US patent disclosure on nonlinear optical guided- mode resonance filter and has published several papers on guided mode resonance filters and devices. Dr. Priambodo has been a reviewer for various professional journals. He is a member of the IEEE Lasers and Electro-Optics Society (LEOS) since 1996. He is also member of honor societies of Eta Kappa Nu and Phi Beta Delta. Dr. Priambodo's research interests include diffractive optics, optical interconnection, quantum optoelectronics, semiconductor lasers, finite-difference timedomain electromagnetic propagation analysis, modulator/receiver and optical waveguide, photonics crystals, quantum electrodynamic and field theory.

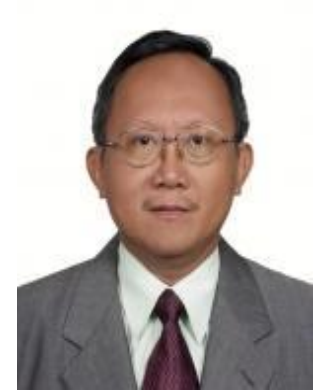

Eko Tjipto Rahardjo, PhD. was born at Pati, Indonesia, on April 22, 1958. He received the Ir. Degree from the Universitas Indonesia, Jakarta in 1981, the MS degree from the University of Hawaii at Manoa, Honolulu in 1987, and the PhD. degree from the Saitama University, Uraw a in 1996, all in electrical engineering. He joined to the Department of Electrical Engineering Universitas Indonesia since 1982 as a teaching assistant. Since 2005 he has been appointed as Professor in electrical engineering. He has been as Chairman of University Senate of Universitas Indonesia in 2011 - 2012. He has also been as Head of Electrical Engineering Department, Universitas Indonesia (2004 - 2008). He was Executive Director of the Quality Undergraduate Education (QUE) in the Department of Electrical Engineering Universitas Indonesia (1999-2004), and was Head of Telecommunication Laboratory Universitas Indonesia (1997-2004). Since 2003, he has been Director of the Center for Information and Communication Engineering Research (CICER), Universitas Indonesia as well as Antenna propagation and Microwave Research Group (AMRG) Group Leader. His research interests include antenna engineering, wave propagation, microwave circuits and communication system and telecommunication system regulations. 